\title{
Acoustically evoked potentials in two cephalopods inferred using the auditory brainstem response (ABR) approach
}

\author{
Marian Y. Hu ${ }^{a}$, Hong Young Yan ${ }^{\text {b, }}{ }^{\text {, Wen-Sung Chung }}{ }^{\mathrm{b}}$, Jen-Chieh Shiao ${ }^{\mathrm{c}}$, Pung-Pung Hwang ${ }^{\mathrm{b}}$ \\ a Institute of Marine Sciences, IFM-GEOMAR, 24105 Kiel, Germany \\ b Institute of Cellular and Organismic Biology, Academia Sinica, Nankang, Taipei, 11529 Taiwan \\ ${ }^{\mathrm{c}}$ Institute of Oceanography, College of Science, National Taiwan University, Taipei, 10617 Taiwan
}

\section{A R T I C L E I N F O}

\section{Article history:}

Received 12 January 2009

Received in revised form 21 February 2009

Accepted 22 February 2009

Available online 9 March 2009

\section{Keywords:}

Hearing

Lateral line

Octopus

Sound reception

Squid

Statocyst

\begin{abstract}
A B S T R A C T
It is still a matter of debate whether cephalopods can detect sound frequencies above $400 \mathrm{~Hz}$. So far there is no proof for the detection of underwater sound above $400 \mathrm{~Hz}$ via a physiological approach. The controversy of whether cephalopods have a sound detection ability above $400 \mathrm{~Hz}$ was tested using the auditory brainstem response (ABR) approach, which has been successfully applied in fish, crustaceans, amphibians, reptiles and birds. Using ABR we found that auditory evoked potentials can be obtained in the frequency range 400 to $1500 \mathrm{~Hz}$ (Sepiotheutis lessoniana) and 400 to $1000 \mathrm{~Hz}$ (Octopus vulgaris), respectively. The thresholds of $S$. lessoniana were generally lower than those of 0 . vulgaris.
\end{abstract}

(C) 2009 Elsevier Inc. All rights reserved.

\section{Introduction}

It has been speculated for more than a century, whether cephalopods can hear. Baglioni (1910) observed that blind Octopus vulgaris responded to water movements and low frequency vibrations by behavioural changes. Fifty years later, Wells and Wells (1956) reported that blind octopus could locate the direction of a sound source which was produced by tapping on the tank. Sepia officinalis responded to a stimulus of $180 \mathrm{~Hz}$ by changing its colour (Dijkgraaf, 1961) and Maniwa (1976) convincingly demonstrated that the squid Todarodes pacificus could be attracted by a pure tone sound of $600 \mathrm{~Hz}$ which was emitted from commercial squid fishing boats. An electrophysiological approach was used by Budelmann and Bleckmann (1988) to demonstrate the detection of water vibrations ranging from $3.5 \mathrm{~Hz}$ to $200 \mathrm{~Hz}$ by the epidermal head lines of juvenile specimens of the cuttlefish $S$. officinalis, but response to higher frequencies (indicating possible underwater audition), were not observed.

Sound perception among cephalopods has been a controversial issue since the early 20th century, due ostensibly to debate regarding the definition of hearing in an aquatic environment. As most cephalopods lack gas filled chambers, such as a swim bladder and, thus, most likely cannot detect the pressure wave component of sound.

\footnotetext{
* Corresponding author. Tel.: +886 3 9880544; fax: +88639871035. E-mail address: hyyan@gate.sinica.edu.tw (H.Y. Yan).
}

However, like fish, cephalopods (Young, 1989) and shrimp (Lovell et al., 2005) have statocysts (otoliths) that in principle can be used to detect whole body motions such as those caused by the displacement component of a sound wave. Young (1960) pointed out that the statocyst might serve as a detector for vibrations, or sound, in a similar way as the vertebrate vestibular system. The cephalopod statocyst with its macula-statolith system shows many comparative features similar to the fish inner ear with the macula-otolith complex. It is well accepted that fish (Webster et al., 1992; Kenyon et al., 1998; Yan, 1998; Fay and Popper, 1999; Yan and Curtsinger, 2000; Simpson et al., 2005) and shrimp (Lovell et al., 2005) have the ability to detect acoustic underwater stimuli of a wide frequency range using either their inner ear (in fish) or statocyst (in shrimp). In these examinations the auditory brainstem response (ABR), an electrophysiological far-field recording method that was originally used in clinical evaluation of the patients' hearing ability (Hall, 1992), had been applied. The ABR technique has never been used on cephalopod species, as these animals have no real brainstem. However, they show the presence of afferents in the statocyst and existence of neural pathway terminating in the brain, indicating that the physiology of cephalopods is suitable for the recording of acoustically evoked potentials (AEPs) with the use of ABR (Williamson and Budelmann, 1985; Hanlon and Messenger, 1996). In a study on European prawn Palaemon serratus, the ABR technique had clearly demonstrated hearing ability via the statocysts ranging from $100 \mathrm{~Hz}$ to $3000 \mathrm{~Hz}$ by this invertebrate (Lovell et al., 2005). The results of this study prompted us to formulate a hypothesis that cephalopod may also detect sound stimuli with frequencies higher than $400 \mathrm{~Hz}$. 
The goal of our study was to investigate whether AEPs can be recorded from cephalopods and whether cephalopods can hear sound frequencies above $400 \mathrm{~Hz}$. To investigate the role of the statocyst in the generation of the AEPs, we also chemically ablated the statocyst function to offer the proof that hearing ability is coded by the statocyst.

\section{Materials and methods}

\subsection{The oval squid Sepioteuthis lessoniana Lesson, 1830}

Forty five specimens of mixed sex and ranging in length from $8 \mathrm{~cm}$ to $20 \mathrm{~cm}$ mantle length (mantle length is from the mantle tip to the end of the gladius superior to the head) were obtained from a local dealer. For transportation back to the laboratory 5 animals were transferred into a 201 plastic sac and slightly anaesthetized with $0.2-$ $0.5 \% \mathrm{MgCl}_{2}$ which is a widely used non-toxic anaesthetic for cephalopods (Messenger et al., 1985). Air pumps with bubble stones were installed to guarantee a proper oxygen supply and the water was kept at a temperature of $18-20{ }^{\circ} \mathrm{C}$ using ice packs inside the cooler box. As soon as they were transported to the laboratory, the animals were held in groups of 10-20 individuals per tank. The flow-through tanks had a volume of $8000 \mathrm{l}$, and the seawater flow rate was approximately $2 \mathrm{l} / \mathrm{min}$. The seawater temperature was kept at a 28 $30{ }^{\circ} \mathrm{C}$, the salinity varied between 30 and $32 \mathrm{ppt}$. The animals were provided with $13 \mathrm{~h}$ of natural daylight and $1 \mathrm{~h}$ of fluorescent light tubes after dark. Each animal was fed daily with 10-20 palaemonid shrimp (approx. $5 \mathrm{~cm}$ body length) which were caught in the estuary waters near the laboratory.

\subsection{The octopus Octopus vulgaris Cuvier, 1797}

Ten specimens of mixed sex ranging in weight from 250-500 g were obtained from a local dealer and transported to the laboratory in 201 plastic tanks with oxygen supply from an air pump. The animals were held in 2501 seawater flow-through tanks with one individual per tank. The flow rate was approximately $1 \mathrm{l} / \mathrm{min}$. and the seawater was kept at a temperature of $28-30{ }^{\circ} \mathrm{C}$. Salinity ranged from 32 to 35 ppt. Each animal was fed with $1-2$ living mangrove crabs $(2-3 \mathrm{~cm}$ carapace length) per day.

\subsection{ABR methodology}

For ABR measurement each test subject was anaesthetized with $1 \% \mathrm{MgCl}_{2}$ in a rectangular plastic tank with air supply, until their mantle movements slowed down and showed no reaction to the touch with a glass rod. Additionally the ambient water was cooled down with the placement of sealed ice packs inside the holding tank to approximately $18{ }^{\circ} \mathrm{C}$ (but not below $15^{\circ} \mathrm{C}$ ). Afterwards the animals were immobilized by an injection of a neuromuscular junction blocker, gallamine triethiodide (Flaxedil; Sigma-Aldrich G-8134, St. Louis, MO., USA) in a $15 \mathrm{mg} / 10 \mathrm{~mL}$ dilution. Flaxedil is a nondepolarising muscle relaxant. It acts by binding with the cholinergic receptor sites in muscle and competitively blocking the transmitter action of acetylcholine (Raghavendra, 2002). Flaxedil has been proven not to influence excitatory postsynaptic potentials (EPSP) in marine mollusk (Panchin et al., 1995), therefore, it is a good choice of anesthetic for use in this experiment. The injected volume was $200 \mu \mathrm{l} / \mathrm{kg}$ in 0 . vulgaris and $120 \mu \mathrm{l} / \mathrm{kg}$ for S. lessoniana. In both species Flaxedil was injected into the arm base. When the mantle movements almost stopped the anaesthetized animals were transferred to a holder inside a rectangular plastic tub. The holder consisted of an acrylic glass board with wholes where the animal was placed on. Additionally a soft rubber tube was used to fix the animals head slightly onto the board by firmly laying the rubber tube around the neck of the squid, the ends of the tube were placed into the holes of the board. For the octopus the rubber band was placed around the narrow connection between arms and head. Except for the fact that the animal was laying on a substrate, slightly fixed, the body could move freely, ensuring the aeration of gills by slow pumping movements. Additionally, the gills were irrigated with fresh seawater by two soft rubber tubes inserted into the mantle cavity, without destroying the cartilage lock in $S$. lessoniana. The flow rate that provided the gills with seawater was $1.5 \mathrm{l} / \mathrm{min}$. The plastic tub was filled with seawater and equipped with an overflow drain tubing connected to a canister under the vibration-free table. The animal was positioned so that the nape of the head and dorsal parts of the mantle margin were $1-2 \mathrm{~mm}$ above the water surface. The whole setup was placed on a vibration isolation table (Kinetic Systems model 1201), which was enclosed in a walk-in sound-proof room $(1.8 \mathrm{~m} \times 1.6 \mathrm{~m} \times 2.7 \mathrm{~m})$. The inside of the room was covered with a fine mesh metal net, i.e., Faraday cage, to filter out noise from electric sources during recording. A rectangular piece of wet Kimwipe tissue paper was placed on the tentacles and parts of the head, to prevent them from drying out during recording.

The acoustically evoked potentials were recorded using two subcutaneous silver electrodes. The recording electrode was placed on the head between the eyes on the "donut-shaped" brain. The reference electrode was positioned on the dorso-anterior margin of the mantle. Both electrodes were pressed firmly against the skin of the test subject. The electrodes consisted of a teflon-insulated silver wire $(0.25 \mathrm{~mm}$ in diameter) with a ca. $1 \mathrm{~mm}$ exposed tip. Wires were fixed with epoxy, and covered by a plastic pipette housing and clamped into micromanipulators. Shielded electrode cables $(60 \mathrm{~cm}$ in length) were plugged into the differential inputs of an $A C$ amplifier (Grass P-15, $40 \mathrm{~dB}$ gain, high-pass at $30 \mathrm{~Hz}$, low-pass at $3000 \mathrm{~Hz}$ ). The ground terminal of the preamplifier was connected via a wire to the water in the tub. To measure the sound level that was transmitted through the water to the test subjects a hydrophone (Celesco LC-10) was placed inside the tub at the same depth adjacent to the animals head. The hydrophone was connected to a Grass P-15 amplifier. Speakers were mounted $1 \mathrm{~m}$ above the testing tub to place the animal outside the near field in order to minimize unnecessary disturbance caused by wave actions $(400 \mathrm{~Hz}$; wavelength $<1 \mathrm{~m}$ ) (Kenyon et al., 1998). For frequencies less than $3000 \mathrm{~Hz}$, a $30 \mathrm{~cm}$ "woofer" speaker (Pioneer; frequency response $19 \mathrm{~Hz}-5 \mathrm{kHz}$ ) was used. Output terminals of the preamplifiers and speakers were hooked to shielded leads that routed through a junction box on the wall of the sound-proof chamber.

\subsection{The ABR recording apparatus and stimulus presentation}

Sound stimuli and ABR waveform recording were accomplished with a Tucker-Davis Technologies (Gainesville, FL, USA) modular rack mount system controlled by an optical cable-linked Dell OptiPlex 1.2 GHz PC containing a TDT AP 2 Digital Signal Process board and running TDT "Bio-Sig" software. Sound stimuli waveforms were generated using TDT "Sig-Gen" software, and fed through a DA1 digital-analog converter, a PA4 programmable attenuator, and a power amplifier (QSC Audio products, Model USA 370 ) which fed the speaker. The stimuli had a duration of $20 \mathrm{~ms}$. Two thousand ABR traces of opposing polarities were recorded and averaged to avoid any stimulus artefacts. For each frequency and sound level tested, two traces were recorded and overlaid to examine conformities. The lowest sound level, where a repeatable ABR trace could be obtained, by overlaying replicate traces, was considered as the threshold. The visual method for threshold determination is the traditional method in ABR audiometry (Jacobson, 1985; Hall, 1992). Such a visual inspection of threshold determination had been proven to be effective and reliable in comparing with Spearman Rank Order correlation coefficient between two replicates (Yan, 1998). 
2.5. Ablation of the statocyst during measurement of acoustically evoked potentials

For ablation of the statocyst, one specimen of the oval squid of medium size (13 cm mantle length) was chosen, and anaesthetized as described above. The test subject was placed with its ventral side up in order to get to access to the statocysts, on the holder inside the tub with fresh seawater supply. The recording electrode was placed $3 \mathrm{~mm}$ anterior of the statocyst and the reference electrode was positioned on the ventral anterior margin of the mantle. After recording of several electrophysiological responses to $1000 \mathrm{~Hz}$ stimuli (at sound levels ranging from $149.4 \mathrm{~dB}$ to $139.4 \mathrm{~dB}$; re $1 \mu \mathrm{Pa}$ ), two micro glass needles clamped into micromanipulators, were inserted into the left statocyst chamber. One glass needle was connected to a syringe via a silicone tube. For chemical ablation purpose the endolymph was sucked out of the statocyst, and with a new syringe, a volume of 1-2 $\mu$ l neomycin (concentration: $0.8 \mathrm{mM}$, solvent: molluscan physiological saline) (Sanchis and Mascitti, 1970) was delivered into the cavity. Neomycin is a known ototoxicant which blocks calcium channels of auditory sensory hair cells (Yan et al., 1991; Harris et al., 2003). Therefore, the chemical ablation experiment was used to investigate the role of statocyst in audition. Afterwards ABR recordings as described above were made in several time points. The differences observed in ABR recordings before and after chemical ablation were compared, offering proof that the statocyst is involved in sound perception.

\section{Results}

\subsection{Electrophysiological responses to auditory stimuli}

Auditory evoked potentials were recorded from both, S. lessoniana and $O$. vulgaris. To prove that the recorded evoked potentials from live animals were genuine and not artefact, we also recorded from one dead individual from each species and only system random noises and no response to any acoustic stimuli given (data not shown) could be obtained. This standardized false check procedure (see Kenyon et al., 1998) validated our recordings. The trace of acoustically evoked potentials from living specimens was a downward peak signal that varies in shape and amplitude. Measured signals had amplitudes ranging from $60 \mathrm{nV}$ to $300 \mathrm{nV}$. In general, recorded potentials from the common octopus had smaller amplitude ( $60 \mathrm{nV}-120 \mathrm{nV}$ ) than those of oval squid (100 nV-300 nV). Additionally a typical frequency dependent shift of traces was observed (Fig. 1). During the $20 \mathrm{~ms}$ stimuli the recorded potential appears earlier with increasing frequency resulting in a latency time difference of $2.5 \mathrm{~ms}$ between $400 \mathrm{~Hz}$ and $1200 \mathrm{~Hz}$.

\subsection{ABR threshold determination}

Thresholds of five individuals of each species were determined visually from the sequentially arranged waveform for each frequency tested, according to method by Kenyon et al. (1998). Fig. 2a shows the evoked waveforms recorded from one $S$. lessoniana in response to a $1000 \mathrm{~Hz}$ sound with sound levels ranging from $149.4 \mathrm{~dB}$ to $129.4 \mathrm{~dB}$ (re $1 \mu \mathrm{Pa}$ at $1 \mathrm{~m}$ ), attenuated in 5 -dB steps. The threshold was reached when two replicate waveforms showed opposite polarities or no common peak could be detected (Fig. 2a at $129.4 \mathrm{~dB}$ ).

\subsection{Audiograms of S. lessoniana and O. vulgaris}

The audiograms obtained for the two species based on the sequential ABR threshold determinations show a hearing range of $400 \mathrm{~Hz}$ to $1000 \mathrm{~Hz}$ for 0 . vulgaris and $400 \mathrm{~Hz}$ to $1500 \mathrm{~Hz}$ for S. lessoniana (Fig. 3). For 400-, 500-, 700 and $800 \mathrm{~Hz}$ no significant difference of thresholds between squid and octopus was observed (t-test $p>0.05$ ), whereas for $600 \mathrm{~Hz}$ and above $800 \mathrm{~Hz}$ the thresholds of $S$. lessoniana were significantly lower than those of 0 . vulgaris ( $t$-test $p<0.05$ ). In addition, 0 . vulgaris failed to respond to acoustical stimuli higher than $1000 \mathrm{~Hz}$ and therefore the upper reach of hearing frequency for 0 . vulgaris was at $1000 \mathrm{~Hz}$ with a sound pressure level of about $150 \mathrm{~dB}$. On the other hand, the hearing frequency of S. lessoniana extended beyond $1000 \mathrm{~Hz}$ and reached up to $1500 \mathrm{~Hz}$ with a threshold of $140 \mathrm{~dB}$. We presented a frequency range of $400 \mathrm{~Hz}$ to $4000 \mathrm{~Hz}$ to the test subjects but they failed to respond to frequencies higher than those mentioned above. On a comparative basis, $S$. lessoniana is characterized by a wider hearing frequency range in combination with lower sound thresholds than of 0 . vulgaris (Fig. 3).

\section{Effects of chemical ablation of the statocyst on acoustically evoked potentials}

The ablation of statocyst function was achieved by injection of neomycin (at a concentration of $0.8 \mathrm{mM}$ ) into S. lessoniana. Prior to the injection, normal evoked brainwaves were observed and recorded (Traces 1 and 2 in Fig. 4). From 0 to 3 min after the injection, AEP signals started showing signs of subtle changes (Traces 3 and 4 in Fig. 4). Three to 6 min after the injection, the first peak as seen previously had disappeared whereas the second upward peak showed altered course and amplitude (Traces 5 and 6 in Fig. 4). These newly formed upward signals become 2-4 small upward peaks until 15 min after the injection (Traces 7 and 8 in Fig. 4). Between 21 and 24 min after the injection, inconsistent wave shapes of the two replicate tracks were observed (Traces 9 and 10 in Fig. 4). Then, no peak could be observed on the recorded evoked brainwaves between 25 and 28 min (Traces 11 and 12 in Fig. 4), probably an indication that sensory hair cells lost their function to respond to acoustical stimuli. After measurement, it was confirmed that the subject was still alive and even at the final time point (almost $3 \mathrm{~h}$ after the injection) of terminating the experiment, the

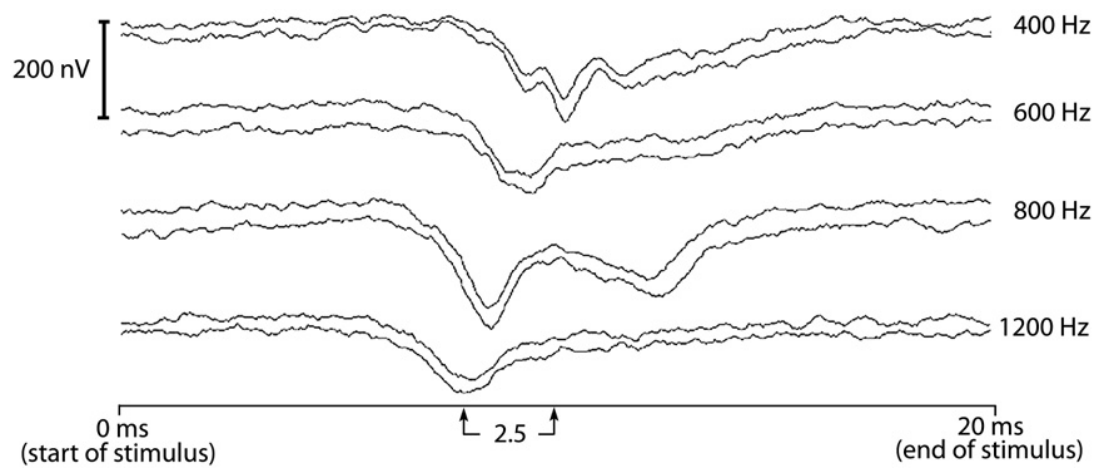

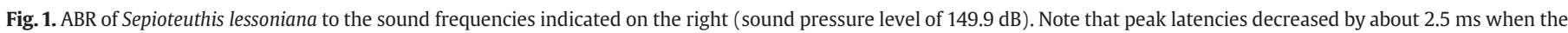
stimulus frequency was increased from 400 to $1200 \mathrm{~Hz}$. 
a
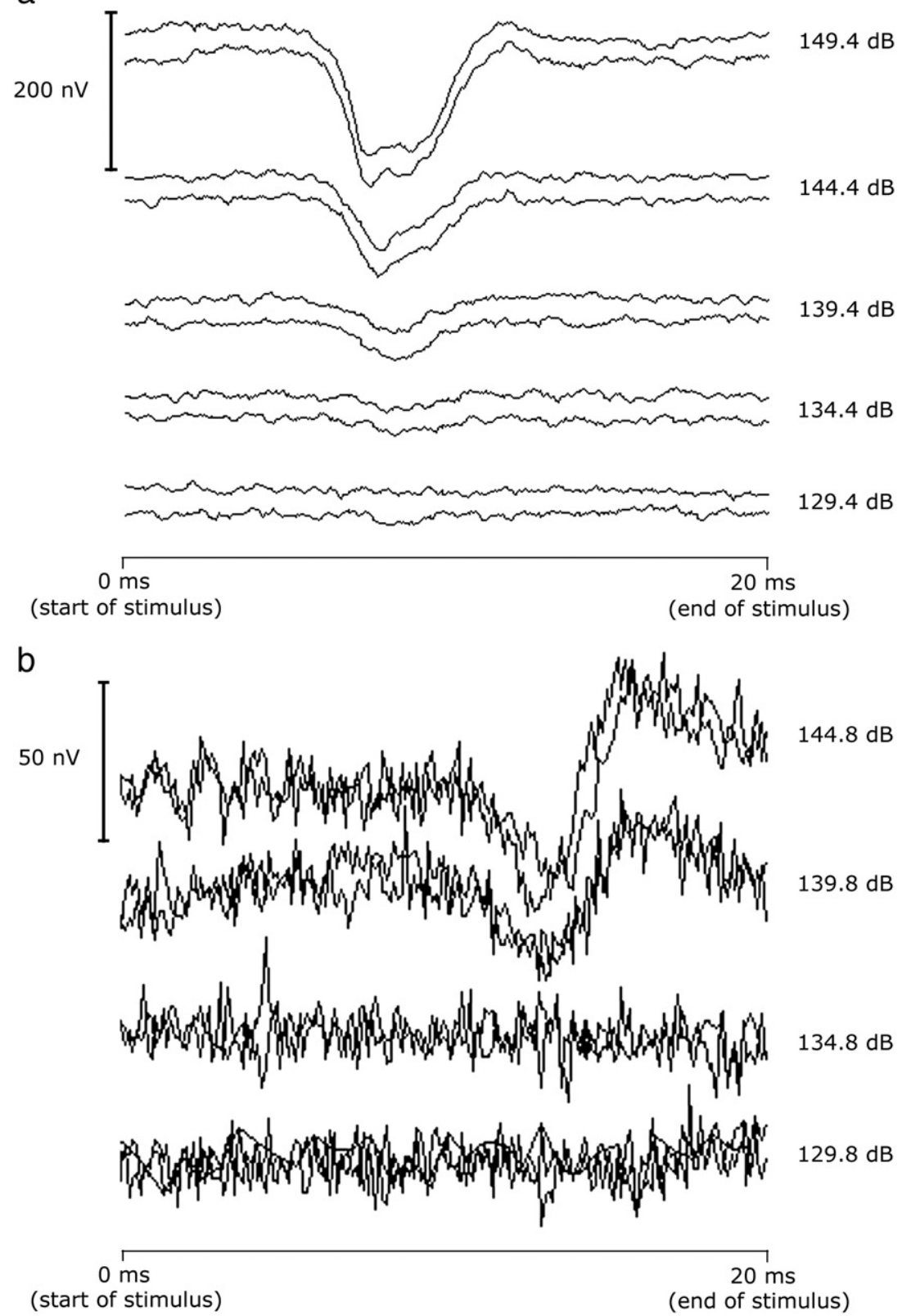

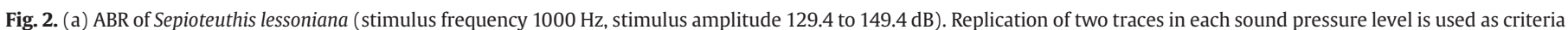

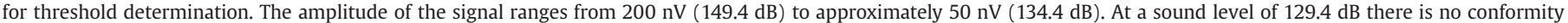

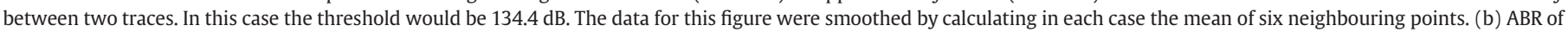

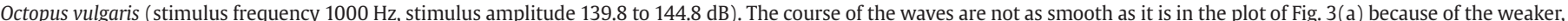

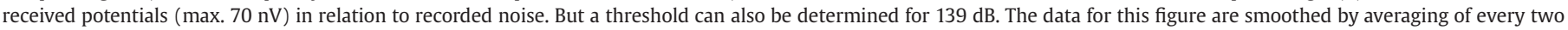
points.

subject was still alive with mantle movement as well as pumping of branchial hearts.

\section{Discussion}

This work has clearly demonstrated that at least two cephalopod species, $S$. lessoniana and 0 . vulgaris are able to detect sounds ranging from $400 \mathrm{~Hz}$ to $1500 \mathrm{~Hz}$ and from $400 \mathrm{~Hz}$ to $1000 \mathrm{~Hz}$, respectively.

Earlier studies demonstrated that cephalopods respond to local (near field) water movements up to $200 \mathrm{~Hz}$ by using their epidermal sensory receptors (Budelmann and Bleckmann, 1988). However, there was no proof for the detection of sounds above $400 \mathrm{~Hz}$ except an observation made by Maniwa (1976) who noted that squids could be attracted by $600 \mathrm{~Hz}$ sounds. Additionally Komak et al. (2005) offered another behavioural evidence for detection of local sinusoidal water movements up to $600 \mathrm{~Hz}$ in the cuttlefish S. officinalis. In the present study, lowest thresholds for both species were around $600 \mathrm{~Hz}$. Essentially, the electrophysiological findings from the present study corroborate with behavioural observations made by Maniwa (1976). Combining both electrophysiological and behavioural data, it is confirmed that cephalopods can detect under water sounds with frequencies higher than $400 \mathrm{~Hz}$.

The question regarding a specialized organ that is responsible for the detection of underwater pressure waves or particle motion above $400 \mathrm{~Hz}$ has been debated by earlier work. Several receptors can be considered as possible candidates for squids' and octopus' response to sound stimuli, such as epidermal head and arm lines and the statocyst (Budelmann and Bleckmann, 1988; Bleckmann et al., 1991). We 


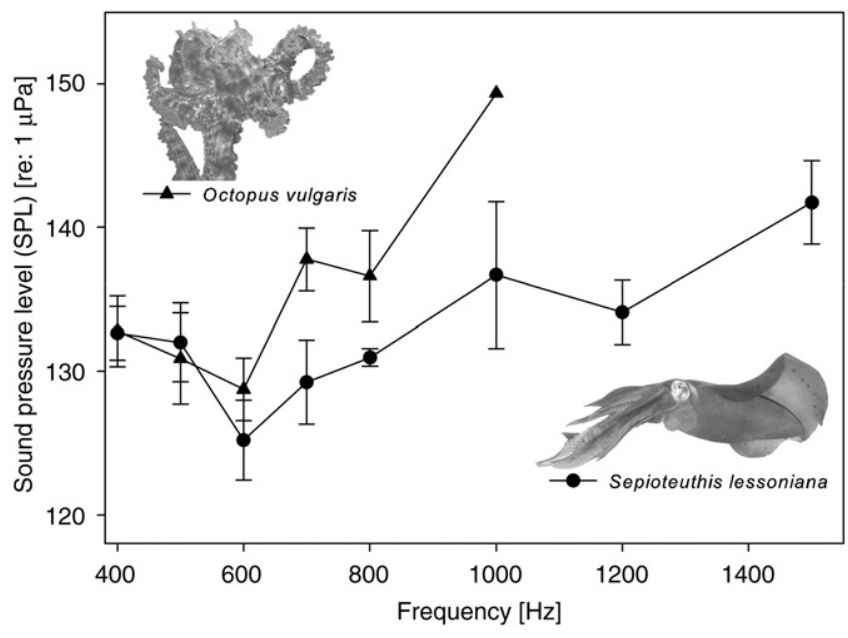

Fig. 3. Auditory thresholds of Octopus vulgaris and Sepioteuthis lessoniana presented in the form of an audiogram. In both cases data were based on five animals. For each animal and frequency, respectively, five threshold values were averaged.

consider the most likely receptor system for frequencies $>400 \mathrm{~Hz}$ to be the statocyst. These equilibrium receptors consist of a statolithmacula complex inside an endolymphe filled cavity (Young, 1989). With respect to the mechanism of sound detection, the statolithmacula complex includes all structural components for detection of the displacement component of a sound wave. Since cephalopods are acoustically buoyant they move with the sound waves and, thus, the higher inertial mass of the statolith causes relative motion between the macula and statolith. Chemical ablation of the sensory hair cells confirms that the AEP response to sound stimulation is mediated by the statocyst organ.

All members of aminoglycoside antibiotics (neomycin is one of them) are known to cause the death of sensory hair cells in the hearing organ (Yan et al., 1991; Lombarte et al., 1993), as well as neuromasts of the lateral line system (Song et al., 1995). Neomycin induced abnormal auditory evoked potentials were very striking and intriguing. Three to $15 \mathrm{~min}$ after neomycin injection, the amplitudes of upward peaks increased when comparing with the amplitudes of potentials prior to the injection. This might indicate that more hair cells were abnormally activated and therefore stronger electric signals were generated. We cannot be sure whether the injection of neomycin in this study caused death of hair cells or physical changes of statocyst parameters (pressure or ionic composition) led to hair cell malfunction, but at least their proper function was disturbed. The cession of evoked potential signals to the sound stimulus after $25 \mathrm{~min}$ and onward might be due to the ototoxic effect of neomycin on the physiological functions of sensory hair cells inside the statocyst. Due to the fact that we only injected neomycin into one statocyst chamber a complete cession of evoked potentioal was unexpected. Thus, it might be possible that the animal was brain dead at the final time point of $25 \mathrm{~min}$, although mantle and branchial hearts were still moving. Nevertheless, the observation before the complete cession of signals supports the possibility that the statocyst contribute to the auditory ability of cephalopods. Further investigations are needed in order to clearly identify the responsible organ.

The cephalopod statocyst shows many comparable features to the fish inner ear such as the macula and otolith inside an endolymph filled cavity, but apart from these similarities there is a major difference: gas filled structures. Gas filled structures that are connected directly or indirectly to the inner ear of fish function as amplifiers to pick up the pressure component of sound and pass it onto the inner ear. Deflation of the swim bladder of goldfish (Yan and Curtsinger, 2000) and removal of gas from otic gasbladder in mormyrid fish (Yan and Curtsinger, 2000) all caused a decrease in the hearing ability. As cephalopods do not have any gas filled chambers, except of Sepia spp. and Nautilus spp., there is no possibility for amplification of sound pressure waves. On a relative scale, the hearing ability of $O$. vulgaris and S. lessoniana is comparable to those of fish without a mechanically coupled gasbladder to the inner ear and is also comparable to hearing ability of prawns, which also have no gas filled structure for the amplification of pressure waves (Lovell et al., 2005). Another striking similarity between vertebrate inferred potentials and those of the two examined cephalopod species is a frequency dependent change in response latency. This is typical for ABR recordings (Hall, 1992; Kenyon et al., 1998). It is concluded that the frequencies detected in both $O$. vulgaris and $S$. lessoniana were in

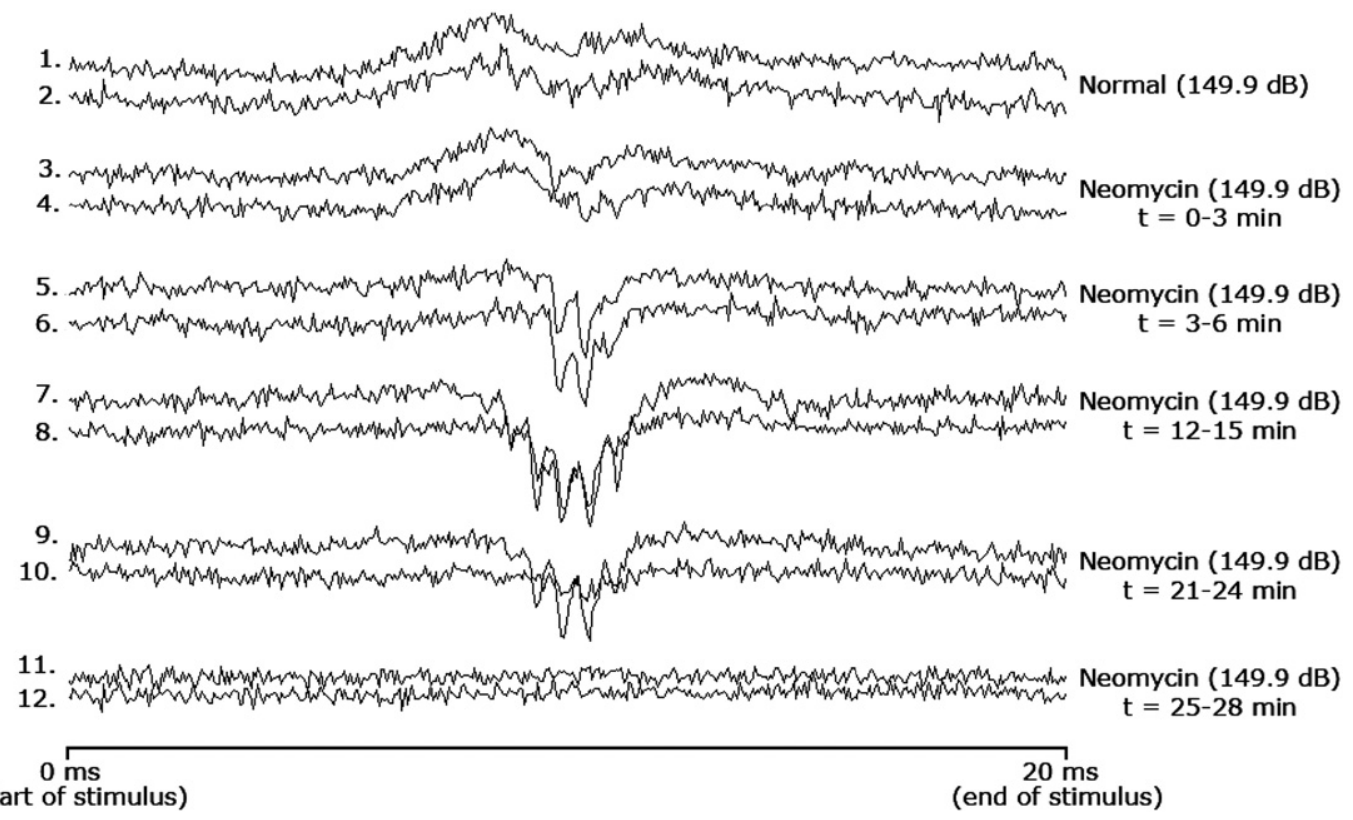

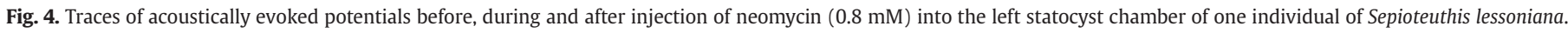

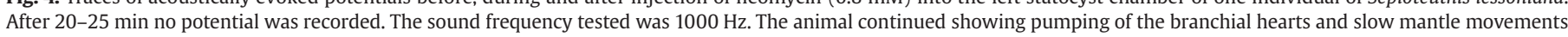
for more than $3 \mathrm{~h}$ until it died. 
the range of other animals that lack gas filled chambers and, thus, these cephalopods are probably only sensitive to the motion of water particle displaced by sound with frequencies up to $1000 \mathrm{~Hz}-1500 \mathrm{~Hz}$.

The differences in audiograms of the oval squid and the common octopus clearly indicated that varying hearing abilities exist among cephalopods. The difference in hearing ability of S. lessoniana compared to 0 . vulgaris could perhaps be explained by long term selection pressure exerted on them by the ecological niches they occupied. The oval squid is a pelagic and group forming organism with very limited hiding possibilities, while on the other hand the common octopus is a demersal organism that resides in rocky habitats and has very strong camouflage ability. In light of this difference in habitat usage the auditory sense would play a role of higher importance for the squid in order to escape from predators before they are visually detected. The ecological importance as well as biological significance for cephalopods to hear sound frequencies in the range as presented in this study needs to be investigated. Sounds in the $400 \mathrm{~Hz}$ to $2000 \mathrm{~Hz}$ range are either produced by anthropogenic, abiotic or animal sources in the marine environment. Odontocete cetaceans are common predators feeding on cephalopods. These animals can produce sounds in the range of $1-20 \mathrm{kHz}$ with sound pressure levels as high as $168 \mathrm{~dB}$ re $1 \mu \mathrm{Pa}$ at $1 \mathrm{~m}$ (Miller, 2006). Especially dolphins that prey on cephalopods can emit sounds in the frequency range of $1-2 \mathrm{kHz}$ with high sound pressure levels (Schultz et al., 1995; Monteiro-Filho and Monteiro, 2001). In respect to the results of this work it can be established, that at least 0 . vulgaris and $S$. lessoniana are able to detect one of their main predators by audition.

\section{Acknowledgements}

This study was supported by a DAAD grant and a NSC scholarship (Tech-Trek-Program 2006) for M. Y. Hu. Partial funding and materials were provided by the Institute of Cellular and Organismic Biology, Academia Sinica. Special thanks are due to Y.T. Shao for invaluable help with the ABR setup. Additional funding supports were provided by the National Science Council of Taiwan NSC 94-2313-B-001-010; NSC 95-2313-B-001-024; NSC 96-2313-B-001-006; NSC 96-3111-B001-002 to HYY as well as an Intramural Thematic Research Grant of Academia Sinica (AS-95-TP-B05) to both HYY and PPH.

These experiments comply with the "Principles of animal care", publication No. 86-23, revised 1985 of the National Institute of Health, and the animal use protocols were approved by the Academia Sinica Institutional Animal Care and Use Committee (No. RFiZOOYH2007012).

\section{References}

Baglioni, S., 1910. Zur Kenntnis der Leistung eigener Sinnesorgane (Gesichtssinn, Tastsinn und Geruchssinn) und des Zentralnervensystems der Zephalopoden und Fische. Z. Biol. 53, 255-286.

Bleckmann, H., Budelmann, B.U., Bullock, T.H., 1991. Peripheral and central nervous responses evoked by small water movements in a cephalopod. J. Comp. Physiol. A $168,247-257$.
Budelmann, B.U., Bleckmann, H., 1988. A lateral line analogue in cephalopods: water waves generate microphonic potentials in the epidermal head lines of Sepia and Lolliguncula. J. Comp. Physiol. A 164, 1-5.

Dijkgraaf, S., 1961. The statocyst of Octopus vulgaris as a rotation receptor. Pubbl. Stn. Zool. Napoli 32, 64-87.

Fay, R.R., Popper, A.P., 1999. Comparative Hearing: Fish and Amphibians. Springer, New York.

Hall, J.W., 1992. Handbook of Auditory Evoked Responses. Allyn and Bacon, Boston.

Hanlon, R.T., Messenger, J.B., 1996. Cephalopod Behaviour. Cambridge University Press, London.

Harris, J.A., Cheng, A.G., Cunningham, L.L., MacDonald, G., Raible, D.W., Rubel, E.W., 2003. Neomycin-induced hair cell death and rapid regeneration in the lateral line of zebrafish. J. Assoc. Res. Otolaryngol. 4, 219-234.

Jacobson, J.T., 1985. An overview of the auditory brainstem response. In: JT, J. (Ed.), The Auditory Brainstem Response. College-Hill Press, San Diego, pp. 3-12.

Kenyon, T.N., Ladich, F., Yan, H.Y., 1998. Comparative study of hearing ability in fishes: the auditory brainstem response approach. J. Comp. Physiol. A 182, 307-318.

Komak, S., Boal, J.G., Dickel, L., Budelmann, B.U., 2005. Behavioural responses of juvenile cuttlefish (Sepia officinalis) to local water movements. Mar. Freshw. Behav. Physiol. 38, 117-125.

Lombarte, A., Yan, H.Y., Popper, A.N., Chang, J.S., Platt, C., 1993. Damage and regeneration of sensory hair cell ciliary bundles in the inner ear of a teleost following treatment with an ototoxic drug. Hear. Res. 64, 166-174.

Lovell, J.M., Findlay, M.M., Moate, R.M., Yan, H.Y., 2005. The hearing abilities of the prawn Palaemon serratus. Comp. Biochem. Physiol. A 140, 89-100.

Maniwa, Y., 1976. Attraction of bony fish, squid and crab by sound. In: Schuijf, A., Hawkins, A. (Eds.), Sound Reception in Fish. Amsterdam, Amsterdam, pp. 271-283.

Messenger, J.B., Nixon, M., Ryan, K.P., 1985. Magnesium chloride as an anaesthetic for cephalopods. Comp. Biochem. Physiol. A 82, 203-205.

Miller, P.J.O., 2006. Diversity in sound pressure levels and estimated active space of resident killer whale vocalizations. J. Comp. Physiol. A 192, 449-459.

Monteiro-Filho, E.L.A., Monteiro, K.D.A., 2001. Low-frequency sounds emitted by Sotalia fluviatilis guianensis (Cetacea: Delphinidae) in an estuarine region in southeastern Brazil. Can. J. Zool. 79, 59-66.

Panchin, Y.V., Sadreev, R.I., Arshavsky, Y.I., 1995. Control of locomotion in marine mullusc Clione limacina. X. Effects of acetylcholine antagonists. Exp. Brain Res. 106, 135-144.

Raghavendra, T., 2002. Neuromuscular blocking drugs: discovery and development. J. R. Soc. Med. 95, 363-367.

Sanchis, C.A., Mascitti, T.A., 1970. The occurrence of peripheral molluscan neurons (Cryptomphallus aspersa). Cell. Mol. Life Sci. 26, 1247-1248.

Schultz, K.W., Cato, D.H., Corkeron, P.J., Bryden, M.M., 1995. Low frequency narrow-band sounds produced by bottlenose dolphins. Mar. Mamm. Sci. 11, 503-509.

Simpson, S.D., Yan, H.Y., Wittenrich, M.L., Meekan, M.G., 2005. Response of embryonic coral reef fishes (Pomacentridae: Amphiprion spp.) to noise. Mar. Ecol., Prog. Ser. 287, 201-208.

Song, J.K., Yan, H.Y., Popper, A.N., 1995. Damage and recovery of hair cells in fish canal (but not superficial) neuromasts after gentamicin exposure. Hear. Res. 91, 63-71.

Webster, D.B., Fay, R.R., Popper, A.N., 1992. The Evolutionary Biology of Hearing. Springer-Verlag, New York.

Wells, M.Y., Wells, J., 1956. Tactile discrimination and the behaviour of blind octopus. Pubbl. Stn. Zool. Napoli 28, 94-126.

Williamson, R., Budelmann, B.U., 1985. The response of the octopus angular acceleration receptor system to sinusoidal stimulation. J. Comp. Physiol. A 156, 403-412.

Yan, H.Y., 1998. Auditory role of the superbranchial chamber in gourami fish. J. Comp. Physiol., A 183, 325-333.

Yan, H.Y., Curtsinger, W.S., 2000. The otic gasbladder as an ancillary auditory structure in mormyrid fish. J. Comp. Physiol. A 186, 595-602.

Yan, H.Y., Saidel, W.M., Chang, J.S., Presson, J.C., Popper, A.N., 1991. Sensory hair cells of fish ear: evidence of multiple types based on ototoxicity sensitivity. Proc. R. Soc. Lond., B 245, 133-138.

Young, J., 1989. The angular acceleration receptor systems of diverse cephalopods. Phil. Trans. R. Soc. Lond., B 325, 189-237.

Young, J.Z., 1960. The statocysts of Octopus vulgaris. Proc. R. Soc. Lond., B 152, 3-29. 